\title{
Notch Band Antenna for Wireless Applications
}

\author{
R. Sangeetha \\ M.E Communication Systems \\ GKM College of Engineering and Technology \\ Chennai - 63, India.
}

\author{
B.Rajalakshmi, M.E \\ Assistant Professor/ECE \\ GKM College of Engineering and Technology \\ Chennai - 63, India.
}

\begin{abstract}
In this project a wideband E-shaped patch antenna using Uslots is to be described. A patch antenna, also known as a rectangular micro strip antenna, is an antenna with a low profile, can be mounted on a flat surface. A wide range of radiation pattern can be achieved with this antenna and it is inexpensive. The wide-band mechanism is explored by investigating the behavior of the currents on the patch. This Eshaped antenna is slotted by using U-slots. A notch band characteristic can be achieved by using $\mathrm{U}$ slots in $50 \mathrm{ohms}$ feed lines. A parametric study is presented with the results showing that the antenna can be operated at $1.0 \mathrm{GHz}$ up to 12.0 $\mathrm{GHz}$ frequency band with return loss of $-30.5 \mathrm{~dB}$. Parameters such as S11 and VSWR also have been improved. The design and simulation of antenna is done by using Ansoft HFSS.
\end{abstract}

\section{Key words}

Microstrip Patch Antenna, U-slot, CPW Feed, HFSS

\section{INTRODUCTION}

A Micro strip or patch antenna is a low profile antenna that has number of advantages. It is light weight, low cost and easy to integrate with MIC's. Patch antenna is also used in many applications such as aircraft, satellite, mobile phones, and cars etc. It consists of a radiating patch on one side of a dielectric which has a ground plane on the other side [1]. The disadvantage of patch antenna is narrow bandwidth, low power, and low efficiency.

However, major disadvantage of patch antenna is narrow bandwidth. There are many methods to overcome this problem such as increasing the height of the substrate, and introducing parasitic elements or modifying the shape of the patch. In this paper E-shaped micro strip patch antenna is designed and analyzed. If two parallel slots are incorporated into the patch, the bandwidth increases [6]. A wide band Eshaped antenna with U-shape slot in its feed is designed to cover $1 \mathrm{GHz}-12 \mathrm{GHz}$ range of frequencies. A broad band radiation pattern is achieved.

\section{DESIGN OF PATCH ANTENNA}

There are different types of slot loaded antennas such as Uslot, V-slot, E-shape and H-shape. In this paper U-slot is inserted in E-shaped antenna's feed to achieve wide bandwidth. The parameters are analyzed by changing the position, length, width of the slot [6]. The length, width, and height of antenna is denoted as (L, W, h). Rogers Duroid substrate is used with relative permittivity $(\mathcal{E r})$ of 2.2 . It is used in high power applications and Rogers substrate is also makes low cost.

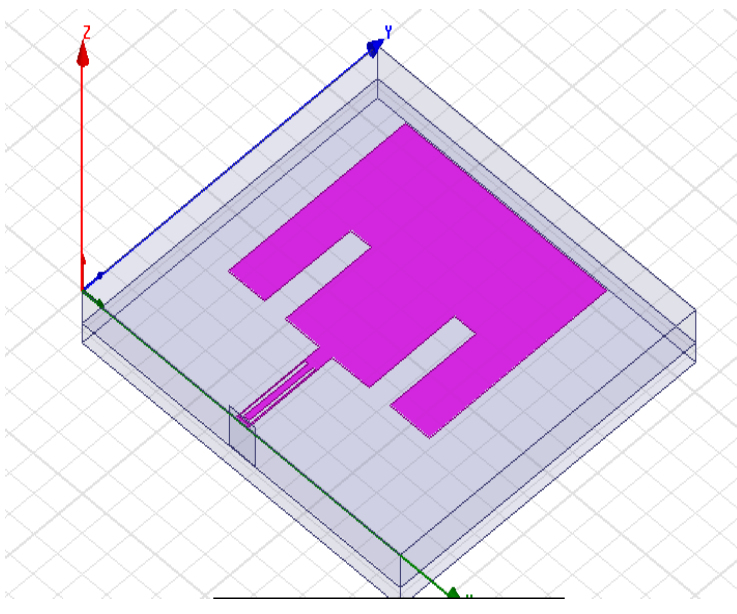

Fig 2.1: E-shaped antenna with U slot

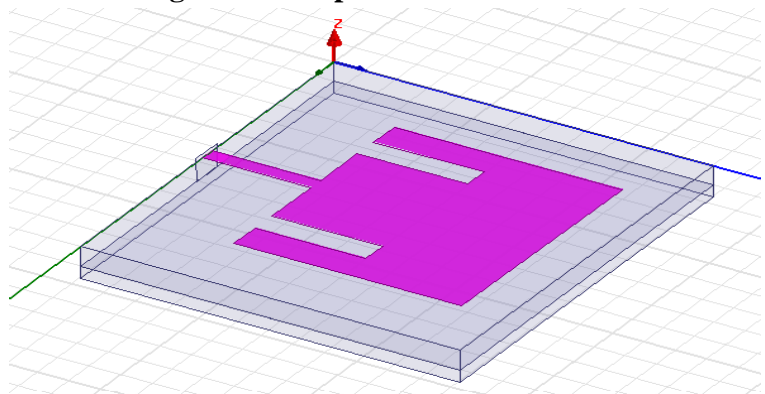

Fig 2.2: E-shaped antenna without U-slot

The parameters of antenna are listed below (in $\mathrm{mm}$ ):

$$
\begin{aligned}
& (\mathrm{L}, \mathrm{W}, \mathrm{h})=(24,26,1.6) \\
& L_{s}=6.2, W_{s}=1.3, P_{s}=7.5
\end{aligned}
$$

The $S_{11}$ is measured on an HFSS software. Ground plane material used here is PEC. By incorporating U-slot in the patch antenna, wide bandwidth can be achieved [6]. It eliminates the interfering signal in particular frequency. The U-slot induces two resonant frequencies, and produces capacitances. The second frequency is induced near the main resonant frequency produced by the micro strip patch antenna. $\mathrm{U}$ slot increases the current flow in the edges of the patch antenna [3]. The length and width of the micro strip patch antenna is calculated by,

The width $\mathrm{W}$ can be calculated by the following equation:

$$
\mathrm{W}=\frac{c}{2 f \sqrt{\frac{\varepsilon_{r+1}}{2}}}
$$

Where,

$\mathrm{c}=$ the speed of light.

$\mathrm{f}_{\mathrm{c}}=$ the resonance frequency

$\varepsilon_{r}=$ the dielectric constant of the substrate. 
Because the electric field lines are moving into the air before entering the dielectric substrate the $\varepsilon_{r}$ will be replaced by $\varepsilon_{\text {reff }}$ which is slightly less than $\varepsilon_{r}$.

The equation of $\varepsilon_{\text {reff }}$ is given by:

$$
\varepsilon_{\mathrm{reff}}=\frac{\varepsilon \mathrm{r}+1}{2}+\frac{\varepsilon \mathrm{r}+1}{2}\left[1+12\left(\frac{h}{W}\right)\right]
$$

Where,

$$
\begin{aligned}
& \varepsilon_{r}=\text { the dielectric constant of the } \\
& \text { substrate } \\
& \mathrm{h}=\text { the height of the dielectric substrate. } \\
& \mathrm{W}=\text { the width of the patch. }
\end{aligned}
$$

The effective length $\mathrm{L}_{\text {eff }}$ can be calculated by the following equation:

$$
L_{e f f}=\frac{\mathrm{c}}{2 \times \mathrm{f}_{\mathrm{c}} \sqrt{\varepsilon_{\mathrm{reff}}}}
$$

The actual length of patch by the following equation:

$$
\mathrm{L}=\mathrm{L}_{\mathrm{eff}}-2 \Delta \mathrm{L}
$$

The ground plane is 6 times larger than the height of the dielectric substrate plus the used length or width. The ground plane can now be calculated as:

$$
\begin{aligned}
& \mathrm{W}_{\mathrm{g}}=6 \mathrm{~h}+\mathrm{W} \\
& \mathrm{L}_{\mathrm{g}}=6 \mathrm{~h}+\mathrm{L}
\end{aligned}
$$

Micro strip line feed is used which is directly contact with one of the radiating edges in the patch antenna. This feed easily control the impedance of the patch. It is also very easy method to fabricate when compared to other feeding methods.

\section{RESULTS AND DISCUSSION}

By changing the length, width and position of the patch antenna, the parameters of the antenna will be varying. When compared with E-shape without U-slot the parameters are improved in E-shape with U-slot. When the slot position is $6 \mathrm{~mm}$, the return loss of the patch is $-31.3 \mathrm{~dB}$ at the operating frequency $6.1 \mathrm{GHz}$ shown in Fig 3.2. When length of the slot is $7.5 \mathrm{~mm}$, the return loss of the patch is- $32.3 \mathrm{~dB}$ at $6.1 \mathrm{GHz}$ shown in Fig 3.3. The return loss of the patch is $-30.9 \mathrm{~dB}$ at $6.1 \mathrm{GHz}$, when the slot width is $1.3 \mathrm{~mm}$ shown in Fig 3.4. Wide band of radiation pattern is achieved shown in Fig 3.5.In Fig 3.7 an E-shaped patch antenna achieves bandwidth of $28.6 \mathrm{~dB}$ in the frequency range of $8.5-10.7 \mathrm{GHz}$ at $-10 \mathrm{~dB}$.

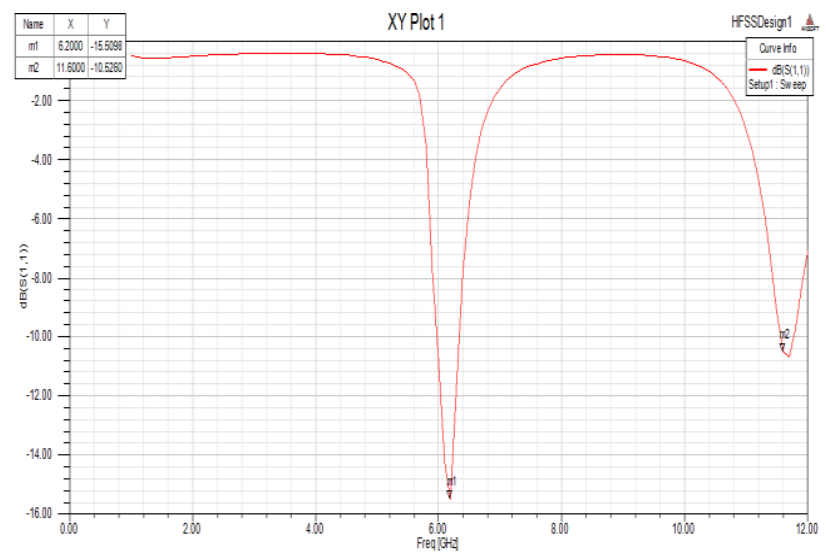

Fig 3.1: Return loss for E-shape without slot

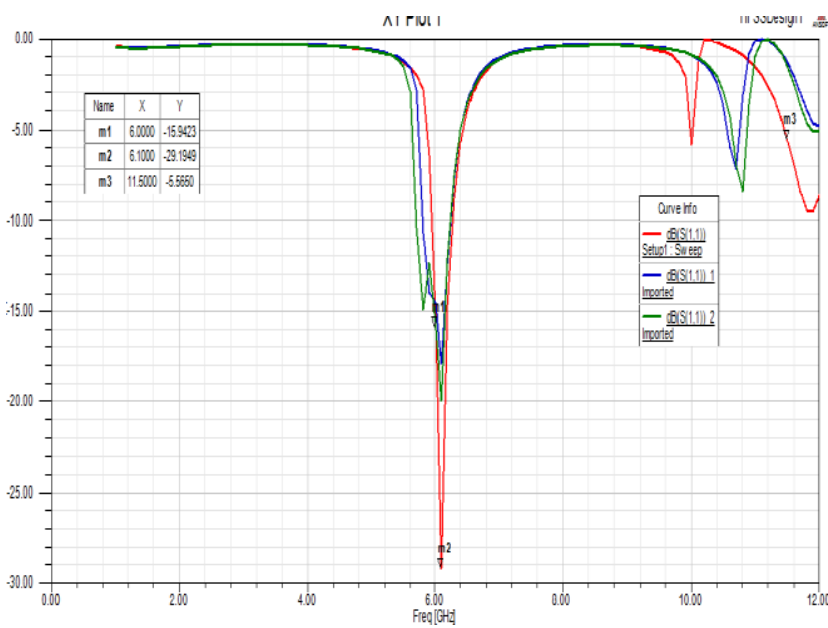

Fig 3.2: Return loss for E-shape with U-slot when changing the slot position.

When position of the slot is $6 \mathrm{~mm}, 6.2 \mathrm{~mm}, 7.1 \mathrm{~mm}$, the return loss of antenna is shown above. Among these, the return loss is minimum at $6.2 \mathrm{~mm}$.

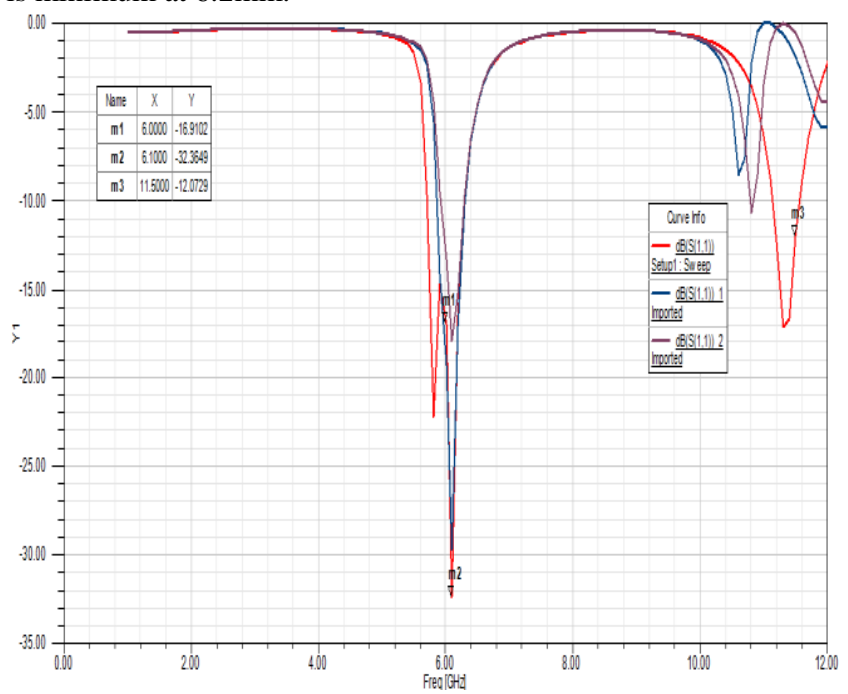

Fig 3.3: Return loss when changing the slot length. When length of the slot is $6 \mathrm{~mm}, 7 \mathrm{~mm}, 7.5 \mathrm{~mm}$, the return loss of antenna is shown above. Among these, the return loss is minimum at $7.5 \mathrm{~mm}$.

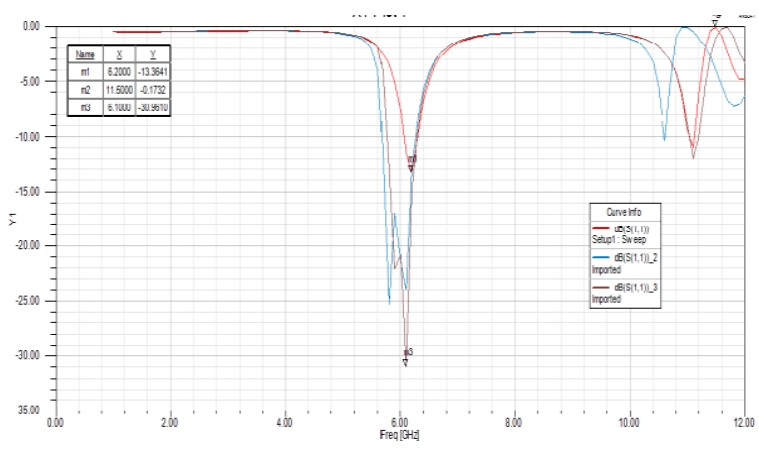

Fig 3.4 Return loss when changing the slot width.

The return loss of antenna is shown above when width of the slot is $1.3 \mathrm{~mm}, 1.5 \mathrm{~mm}, 1.8 \mathrm{~mm}$. Among these, the return loss is minimum at $1.3 \mathrm{~mm}$. 


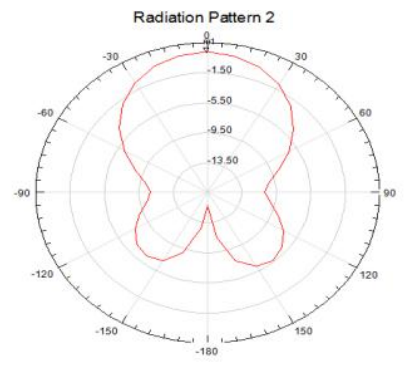

Fig 3.5: Radiation pattern of E-shaped patch antenna. Broad band of radiation pattern is achieved for the antenna and HPBW of this antenna is 1.3.

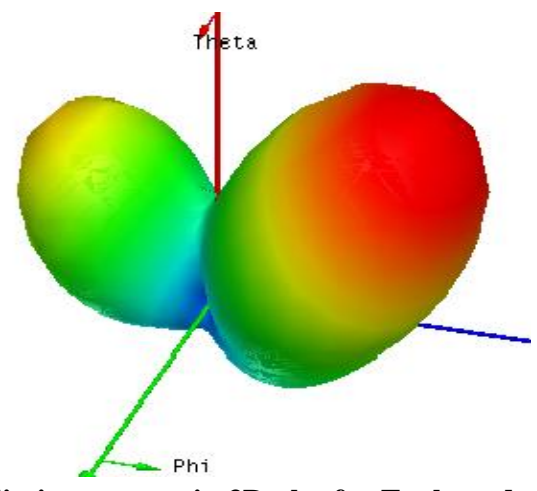

Fig 3.6 Radiation pattern in 3D plot for E- shaped antenna with U-shape slot

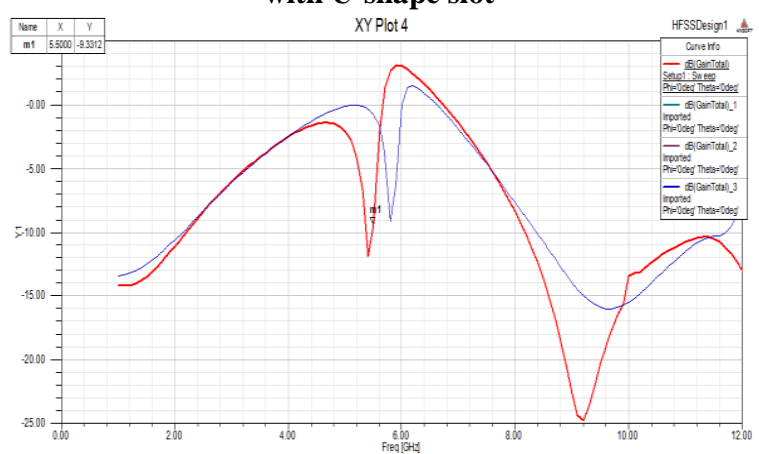

Fig 3.5: Gain of E- shaped antenna with U-shape slot.

High gain can be obtained from this antenna.

\section{CONCLUSION}

An E-shaped wideband micro strip patch antenna using Rogers substrate has been designed, simulated, optimized and analyzed using HFSS (High Frequency Structure Simulator) software version 13. A parametric study is presented with the results showing that the antenna can be operated at $1.0 \mathrm{GHz}$ up to $12.0 \mathrm{GHz}$ frequency band. Parameters such as S11 and VSWR also have been improved. Omni directional radiation pattern is obtained.

\section{REFERENCES}

[1] C.A.Balanis, Antenna Theory: Analysis and Design, Second Edition, New York, John Wiley and Sons, 1997.

[2] R. Garg. P. Bhartia, I. Bahl and A. Ittipiboon, Microstrip Antenna Design Handbook, Norwood, MA, Artech House, 2001.

[3] Rajkumar, P. Malathi, "On The Design of CPW-Fed Ultra Wideband Triangular Wheel Shape Fractal Antenna", Rajkumar, P. Malathi, International Journal of Microwave and Optical Technology, Vol.5, No.2, March 2010.

[4] D. Singh, C. Kalialakis, P. Gardner, and P. S. Hall, "Small H-shaped patch antennas for MMIC applications," IEEE Trans. Antennas Propag., vol. 48, pp. 1134-1141, Jul. 2000.

[5] T. Huynh, and K. F. Lee, " Single-Layer Single Patch wideband Microstrip Antenna," Electronics Letters, 31, 16, August 1995, pp. 13 10-1312.

[6] F. Yang, X. X. Zhang, X. Ye, and Y. Rahmat-Samii, "Wide-band E-shaped patch antennas for wireless communications," IEEE Trans. Antennas Propag., vol. 49, no. 7, pp. 1094-1100, Jul. 2001.

[7] T. Huynh and K. F. Lee, "Single-layer single-patch wideband microstrip antenna," Electron. Lett., vol. 31, no. 16, pp. 1310-1312, Aug. 1995.

[8] F. Tong and T. P. Wong, "Circularly Polarized U-Slot Antenna," IEEE Transactions on Antennas and Propagation, AP- 55,8, August 2007, pp. 2382-2385 .

[9] K. F. Tong and T. P. Wong, "Circularly Polarized USlot Antenna," IEEE Transactions on Antennas and Propagation, AP-55,8, August 2007, pp. 2382-2385.

[10] High Frequency Structure Simulation (H F S S), Version 13, Ansoft Corp. 